\title{
SALA VERDE UNIFESO: ESPAÇO DE EDUCAÇÃO SOCIOAMBIENTAL
}

Ana Maria Gomes de Almeida ${ }^{1}$
Luiz Antônio de Souza Pereira $^{2}$

Resumo: Em tempos de crise socioambiental, o presente relato de experiência descreve e analisa as atividades e estratégias adotadas pela Sala Verde UNIFESO - do Centro Universitário Serra dos Órgãos, desde a inauguração, em 2014, até o final do ano letivo de 2019, com base nos relatórios anuais enviados ao Ministério do Meio Ambiente (MMA). Os resultados apontam uma Sala Verde atuante na região, com a realização de variadas atividades, propostas e coordenadas por docentes da instituição, envolvendo professores, estudantes, funcionários e a população de uma forma geral.

Palavras-chave: Sala Verde; Educação Socioambiental; Responsabilidade Social.

Abstract: In times of socio-environmental crisis, the present experience report and analyzes the activities and implemented by Sala Verde UNIFESO - of the Serra dos Órgãos University Center, since its inauguration in 2014, until the end of the 2019 academic year, based on reports sent to Ministry of the Environment (MMA). The results point to a Green Room operating in the region, with various activities, proposed and coordinated by the institution's professors, involving teachers, students, employees and the population in general.

Keywords: Green Room; Socio-environmental Education; Social Responsability.

\footnotetext{
${ }^{1}$ Centro Universitário Serra dos Órgãos. E-mail: anamariaalmeida@unifeso.edu.br, Link para o Lattes: http://lattes.cnpq.br/5830349878151642

2 Centro Universitário Serra dos Orgãos. E-mail: luizpereira@unifeso.edu.br, Link para o Lattes: http://lattes.cnpq.br/3760286370273503
} 


\section{Introdução}

A Educação Ambiental (EA) emerge na segunda metade do século $X X$ num contexto do aumento da poluição do ar, dos recursos hídricos e do solo, da perda da biodiversidade e suas consequências à saúde e qualidade de vida humana. Não por acaso, o termo Environmental Education foi originalmente concebido, em 1965, durante a Conferência de Educação da Universidade de Keele, na Grã-Bretanha. "Na ocasião, foi aceito que a Educação Ambiental deveria se tornar uma parte essencial da educação de todos os cidadãos e seria vista como sendo essencialmente conservação ou ecologia aplicada" (DIAS, 2004, p. 78).

Não tardou para a problemática atingir a escala internacional e planetária. Em 1972, em Estocolomo, na Suécia, a Conferência das Nações Unidas sobre o Meio Ambiente Humano, um marco na discussão ambiental, estabeleceu um Plano de Ação Mundial, no qual se encontra a criação de um Programa Internacional de Educação Ambiental. Logo em seguida, as Conferências de Belgrado (1975) e Tbilisi (1977) estabeleceram os princípios que nortearam a Educação Ambiental em nível mundial (DIAS, 2004; GUIMARÃES, 2007; LOUREIRO, 2012).

Para o desenvolvimento da $E A$, foi recomendado que se considerassem todos os aspectos que compõem a questão ambiental, ou seja, os aspectos políticos, sociais, econômicos, científicos, tecnológicos, culturais, ecológicos e éticos; que a EA deveria ser resultado de uma reorientação e articulação de diversas disciplinas e experiências educativas (DIAS, 2004, p. 82-83).

Porém, no Brasil, a EA foi introduzida por órgãos ambientais, como a Secretaria Especial do Meio Ambiente (SEMA), desconsiderando a discussão internacional e privilegiando as abordagens ecológica e conservacionista (DIAS, 2004; GUIMARÃES, 2007; LOUREIRO, 2012; LAYRARGUES; LIMA, 2014).

Para romper a associação da temática ambiental apenas aos elementos e processos naturais, na Conferência das Nações Unidas para o Desenvolvimento e Meio Ambiente, realizada no Rio de Janeiro, em 1992, foi proposto o termo socioambiental (MENDONÇA, 2001).

Segundo a Rede Brasileira de Educação Ambiental (REBEA), as políticas públicas de EA no país são oriundas:

De mais de 30 anos de interação entre educadores ambientais, especialistas, sociedade civil organizada e órgãos públicos ambientais e educacionais, e se mostra cada vez mais importante nos processos de conservação da natureza e de construção da sustentabilidade (REBEA, 2019, p.1). 
De acordo com Layrargues e Lima (2014), no Brasil, é possível identificar a existência de três macrotendências político-pedagógicas da EA a partir da década de 1990: conservacionista, pragmática e crítica. De modo que a EA não deve ser denominada de forma genérica, sem qualificá-la, e torne-se plural, de acordo com a opção político-pedagógica que serve de base para as práticas educativas (LOUREIRO, 2012; LAYRARGUES; LIMA, 2014).

A macrotendência político-pedagógica crítica surge como uma alternativa, em oposição às conservadora e pragmática, ao trazer as dimensões política e social da educação e da vida. Contextualiza e politiza o debate ambiental e social, vistos como indissociáveis. Do ponto de vista pedagógico, nutriu-se do pensamento freireano, possuindo como adjetivos e conceitos-chave participação, emancipação, democracia, cidadania, justiça social e transformação social (LAYRARGUES; LIMA, 2014).

A perspectiva crítica da EA encontra-se presente, de certo modo, na Política Nacional de Educação Ambiental (PNEA), Lei n 9.975 de 27 de abril de 1999, uma vez que materializa os princípios e objetivos definidos nos principais eventos internacionais sobre o tema. $E$, sobretudo no âmbito acadêmico, nas pesquisas e obras de Loureiro (2012), Reigota (2009), Guimarães (2007), entre outros.

Garcia et al. (2020), ao analisarem os avanços e retrocessos ao longo das duas décadas da PNEA, apontam um elevado aumento do número de artigos publicados com a expressão "Educação Ambiental" no Google Acadêmico, entre 1999 e 2019. Saltam de 705, em 1999, para 12 mil em 2019, o que significa o total de 148697 publicações no período assinalado.

Apesar do aumento do número de publicações, as autoras pontuam como maiores fragilidades nessas duas décadas: a dependência de ações personalizadas e pontuais; a escassez de orçamentos; o foco em datas comemorativas; ausência da abordagem crítica e a ausência da interdisciplinaridade e da transversalidade do tema EA (GARCIA, 2020).

No bojo das discussões atuais sobre a educação socioambiental, este trabalho se propõe a relatar a experiência adquirida pela Sala Verde Unifeso Centro Universitário Serra dos Órgãos - desde a sua fundação, em 2014, até o ano de 2019, considerando que:

A solução da crise ambiental - crise global e planetária - não poderá surgir apenas através de uma gestão racional da natureza e dos riscos da mudança global. A crise ambiental leva-nos a interrogar o conhecimento do mundo, a questionar este projeto epistemológico que tem buscado a unidade, a uniformidade e a homogeneidade; este projeto que anuncia um futuro comum, negando o limite, o tempo, a história; a diferença, a diversidade, a outridade (LEFF, 2007, p. 194). 
Propusemo-nos a começar falando em linhas gerais sobre o Unifeso para que o leitor possa se situar em relação ao espaço geográfico, econômico, social, histórico, ambiental em que está inserida a Sala Verde.

Abordamos em seguida o que vêm a ser as Salas Verdes no contexto nacional e, mais especificamente, o que motivou a criação da Sala Verde Unifeso.

As atividades desenvolvidas pelo espaço são relatadas adiante, momento em que procuramos de forma objetiva mostrar sua evolução ao longo do tempo e a ampliação de suas ações, assim como as dificuldades e desafios encontrados.

\section{O Centro Universitário Serra dos Órgãos - Unifeso}

O Centro Universitário Serra dos Órgãos - Unifeso, mantido pela Fundação Educacional Serra dos Órgãos, fundada em 20 de janeiro de 1966, situa-se em Teresópolis, na região serrana do estado do Rio de Janeiro.

O município conta com uma área de $773338 \mathrm{~km}^{2}$ e uma população estimada de 184240 habitantes, segundo dados do Instituto Brasileiro de Geografia e Estatística (IBGE, 2021). A taxa de alfabetização no município vem crescendo ao longo das últimas décadas - de $81 \%$, em 1991, para $87,5 \%$,em 2000 , e para $93,5 \%$, em 2010. O potencial econômico do município é marcado por uma vocação para a produção rural de hortaliças, para o turismo, além de se constituir um polo urbano de serviços.

O Unifeso é, sem dúvida, a maior organização econômica, políticosocial, educacional e cultural da cidade. A instituição busca atender as demandas de formação desde a educação básica até ao ensino de pósgraduação. Destaca--se ainda na área da assistência à saúde, mantendo especialmente um hospital de ensino que é referência na região. É a maior empresa privada na geração de empregos e em expressividade de sua folha de pagamento. Insere-se também nos movimentos artístico-culturais com o Centro Cultural FESO Pro-Arte e mantém sua participação nos movimentos comunitários.

A principal área de atuação do Unifeso é o ensino, contemplando a educação básica, a graduação e a pós-graduação. Decorrente das atividades de ensino e com elas articuladas, atua na oferta de serviços assistenciais, de atividades culturais e no desenvolvimento científico e tecnológico nas áreas de Saúde, Humanas e Sociais e Tecnologia.

A sustentabilidade socioambiental é um dos princípios norteadores da conduta institucional e da formação ofertada no Unifeso em todos os seus segmentos de ensino e cursos. A concepção de sustentabilidade socioambiental, defendida como um princípio de ação e formação, pressupõe uma relação equilibrada com o ambiente em sua totalidade, considerando que todos os elementos afetam e são afetados reciprocamente pela ação humana. 
A sustentabilidade, portanto, diz respeito às escolhas sobre as formas de produção, consumo, habitação, comunicação, alimentação, transporte e também nos relacionamentos entre as pessoas e delas com o ambiente, considerando os valores éticos, solidários e democráticos (UNIFESO, 2016).

\section{Das Salas Verdes à Sala Verde Unifeso}

As Salas Verdes são uma iniciativa do Ministério do Meio Ambiente (MMA), que no ano 2000 lançou o primeiro edital com o intuito de incentivar a construção de espaços educativos que discutam a problemática socioambiental. Atualmente, há 639 Salas Verdes no país, localizadas em 475 municípios. Esses espaços são mantidos, sobretudo, por órgãos ambientais, organizações não governamentais (ONGs) que atuam na área ambiental e instituições de ensino.

Em 2013, o Unifeso, sob a coordenação da professora Ana Maria Gomes de Almeida, Diretora do Centro de Ciências Humanas e Sociais (CCHS), formou um grupo constituído com quase uma dezena de docentes para atender a edital e constituir o espaço a ser contemplado com a chancela do MMA.

O projeto, ligado à Diretoria de Pós-Graduação, Pesquisa e Extensão (DPPE), tem como objetivo orientar e conscientizar a sociedade teresopolitana sobre as várias faces da Educação Ambiental de modo a mudar os hábitos, conceitos e atitudes em relação ao meio ambiente. Propõe-se como um catalisador de discussão, vivência e atualização de atividades (projetos, eventos, cursos) que possam contribuir para a formação de novos paradigmas de vida e sustentabilidade ambiental.

Coerente com o Programa de Sustentabilidade Ambiental previsto no Plano de Desenvolvimento Institucional 2018-2023, visa, ainda, aperfeiçoar as condições de sustentabilidade ambiental no UNIFESO, contribuindo para o enfrentamento de desequilíbrios ambientais presentes na região, em sistemática articulação com as demais regiões. Como uma proposta de natureza multi e interdisciplinar, o desenvolvimento de suas atividades é feito a partir da integração das áreas acadêmica e administrativa, bem como do trabalho em conjunto de gestores, professores, estudantes e funcionários, além de diversos parceiros.

Desde a inauguração, em 2014, sob a coordenação da professora doutora Ana Maria Gomes de Almeida, a Sala Verde Unifeso tem contado com a participação efetiva de 12 professores com diferentes formações (pedagogia, geografia, biologia, engenharia ambiental, direito, medicina, ciências contábeis e astronomia), que têm em comum a atuação profissional na área ambiental em suas múltiplas facetas e complexidades que transcendem a formação disciplinar. Em 2019, a equipe foi acrescida de uma representante da educação básica da instituição. 


\section{Ações da Sala Verde Unifeso}

O MMA solicita às Salas Verdes que enviem anualmente um relatório informando as ações desenvolvidas: nome da ação/projeto, data/período de realização, breve descrição, número de participantes e o registro fotográfico.

Os dados e as informações a seguir foram extraídas dos relatórios anuais da Sala Verde Unifeso enviados ao MMA entre os anos de 2014 e 2019.

No Gráfico 1, é possível observar o número de eventos realizados pela Sala Verde Unifeso. O primeiro ano, apesar de apresentar a menor quantidade de atividades no período, foi extremamente importante para a construção do seu espaço físico e virtual e da equipe formada por professores de diversos cursos e centros de ensino, pesquisa e extensão da instituição.

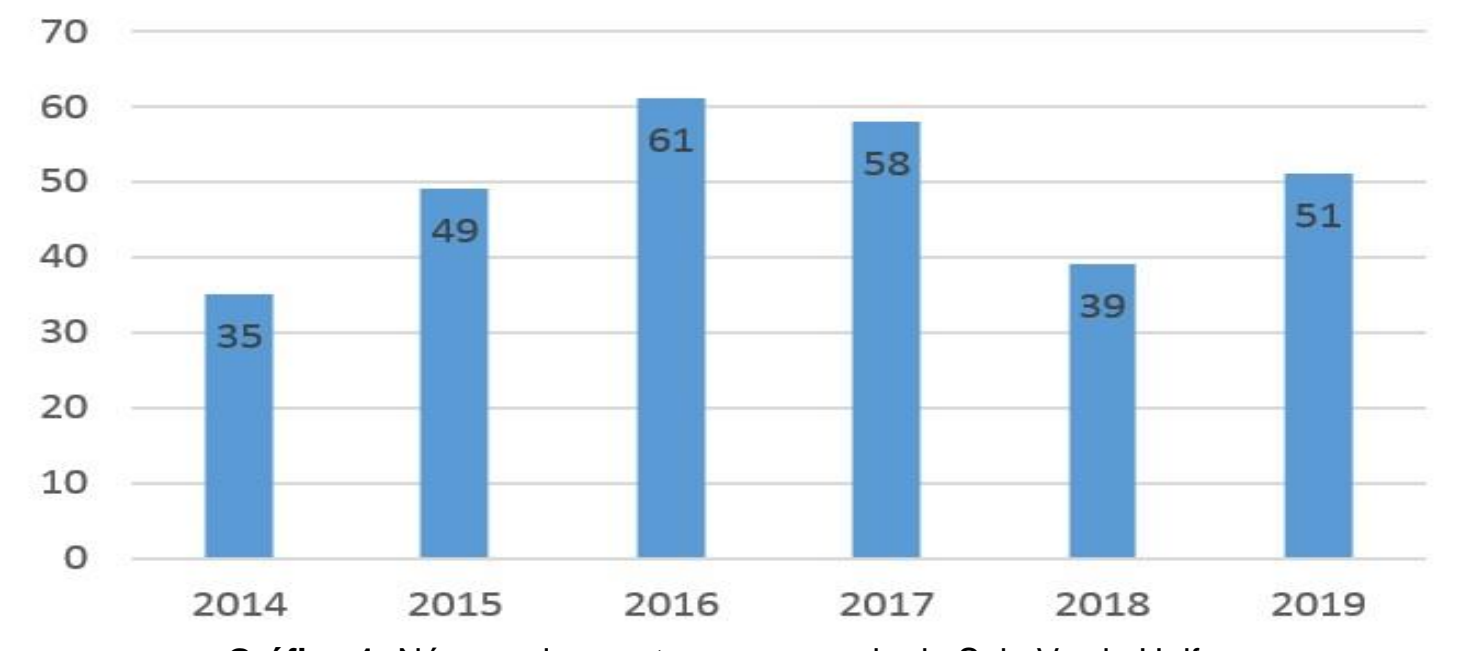

Gráfico 1: Número de eventos com o apoio da Sala Verde Unifeso

Fonte: Elaborado pelos autores (2020).

Os anos de 2015, 2016 e 2017 demonstraram a expansão das atividades e a consolidação da Sala Verde na instituição. A redução das atividades em 2018 é atribuída ao conturbado momento político, econômico e social vivenciado nas escalas municipal, estadual e federal. Tanto que em 2019 o número de atividades é um pouco superior à média de 48,8 eventos por ano. Ao todo, foram realizadas 293 atividades.

As atividades foram agrupadas em quatro grupos (Gráfico 2). 0 primeiro é composto, sobretudo, por palestras. Também foram inseridos os seminários, apresentação de trabalhos, reuniões, cursos e entrevistas. A principal atividade foi o "Café Científico" promovido pelo curso de Ciências Biológicas. Na Figura 1 , temos a tradicional foto de encerramento de mais um Café Científico com a presença de todos os envolvidos (palestrante, professores e estudantes). Ao todo foram realizadas 114 atividades dessa natureza, que corresponde a $38,9 \%$, sendo a mais realizada em quatro dos seis anos. 


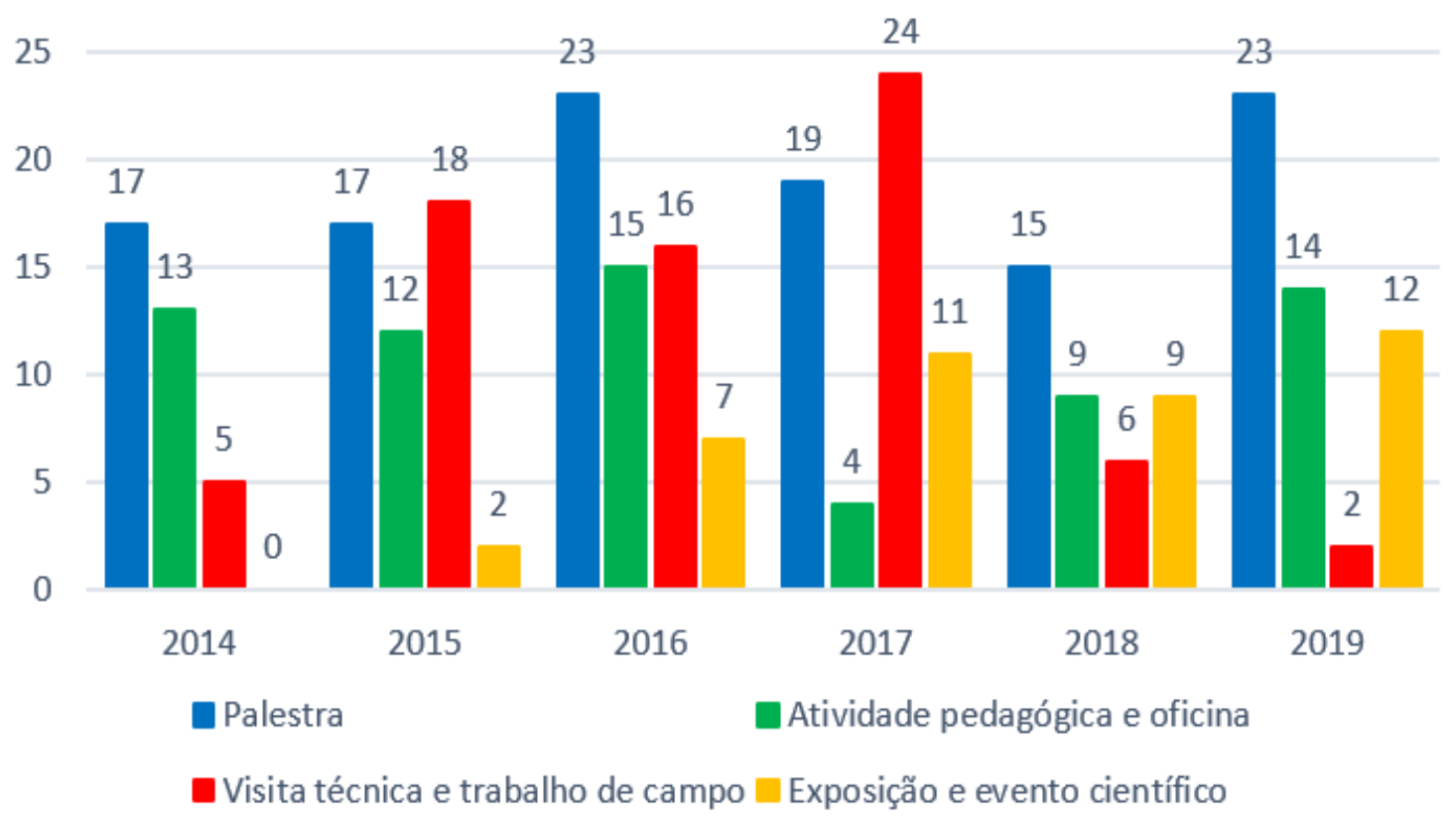

Gráfico 2: Tipos de atividades da Sala Verde Unifeso

Fonte: Elaborado pelos autores (2020).

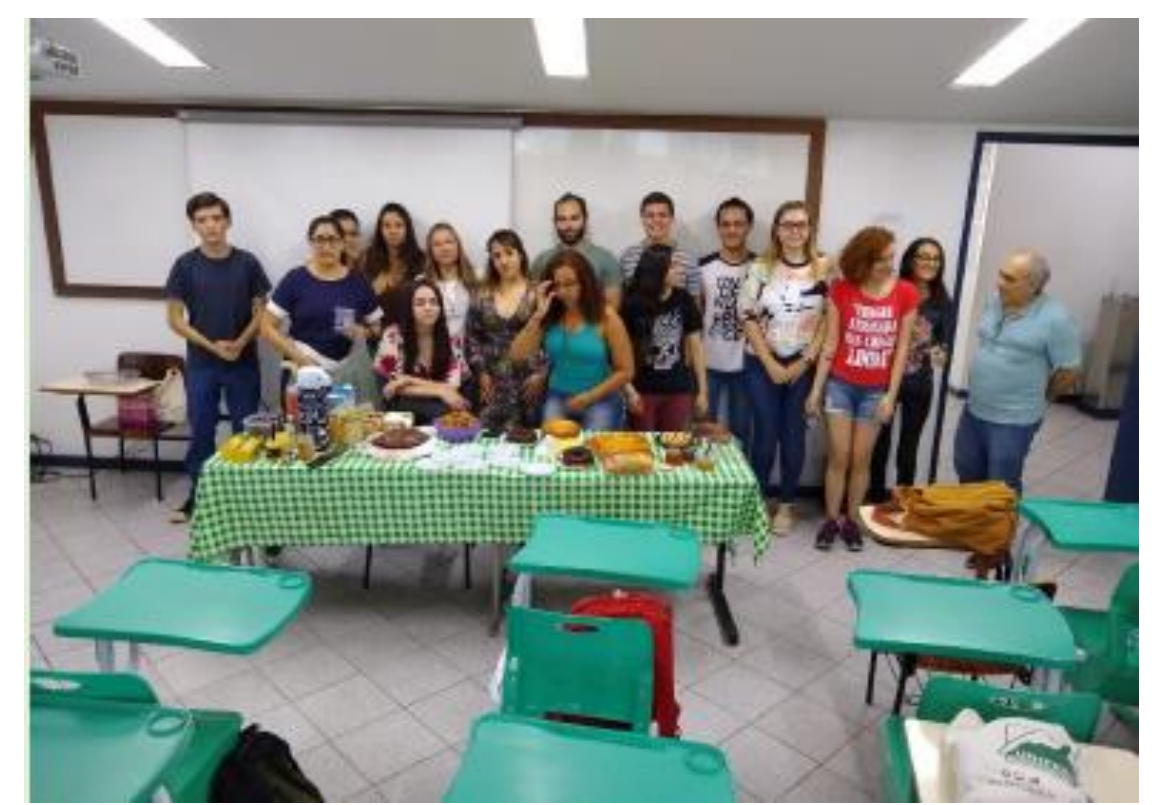

Figura 1: Café Científico sobre o tema agroecologia

Fonte: Unifeso (2018).

O grupo formado pelas visitas técnicas e trabalhos de campo (Figura 2) alcançou 71 atividades, correspondendo a 24,2\%. Em 2015 e 2017, os trabalhos de campo e as visitas técnicas foram as atividades mais realizadas pela Sala Verde Unifeso. 


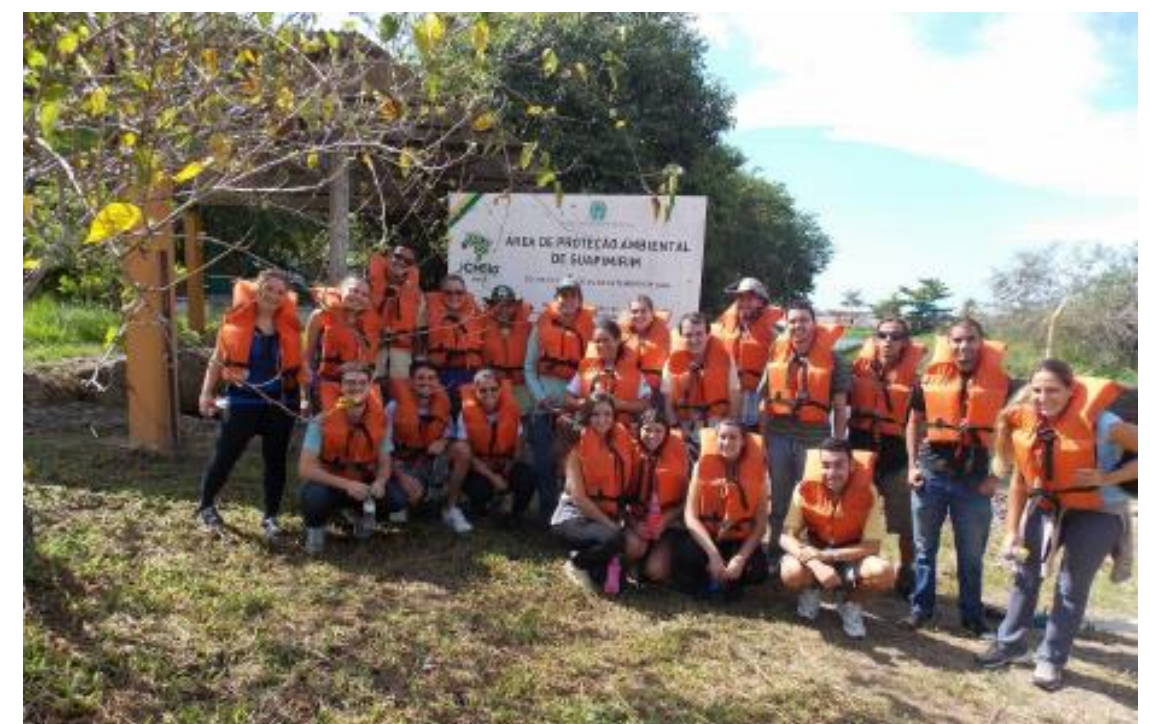

Figura 2: Visita Técnica à Area de Proteção Ambienttal (APA) de Guapimirim Fonte: Unifeso (2014).

Cabe registrar que a maior parte das visitas técnicas e trabalhos de campo foi organizada e executada pelos cursos de Engenharia Ambiental e Sanitária e de Ciências Biológicas. A redução significativa dessas atividades nos dois últimos anos está intimamente relacionada à conclusão da última do curso de Engenharia Ambiental e Sanitária na instituição.

O grupo constituído pelas atividades pedagógicas, oficinas, ecocines, incluindo a exibição dos vídeos do Circuito Tela Verde, jogos educativos e a produção de material informativo constitui-se de 67 atividades, $22,8 \%$ do total (Figura 3). A maior parte dessas atividades foi elaborada por professores do curso de Pedagogia e realizada nos espaços educativos da instituição e da rede pública local com estudantes da educação básica.

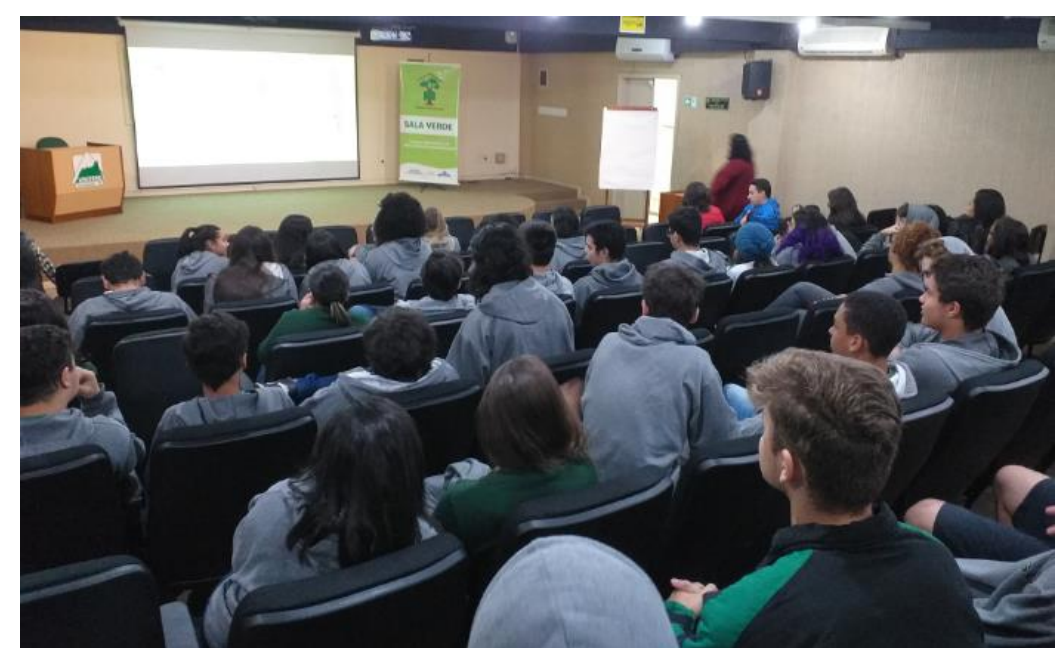

Figura 3: Exibição de curtas do Circuito Tela Verde sobre o tema Água aos estudantes do CESO na VI Semana do Meio Ambiente do Unifeso

Fonte: Registro dos autores (2019). 
Uma parte dos materiais informativos e educativos socioambientais produzidos, em particular, por docentes e discentes do curso de Pedagogia e do Centro Educacional Serra dos Órgãos (CESO), foi publicada e disponibilizada no formato de cartilhas (Figura 4). Cabe registrar a contribuição da Editora Unifeso na confecção desses materiais.

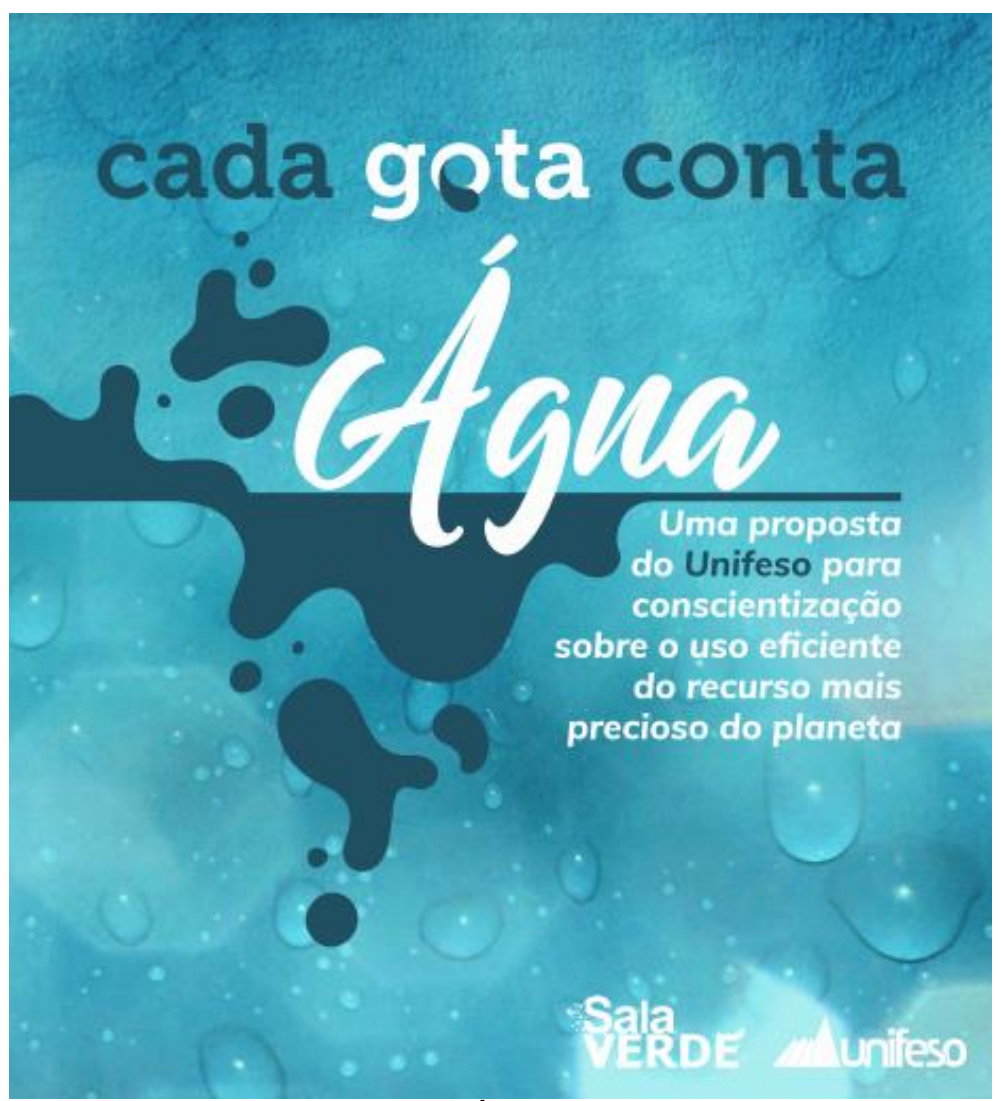

Figura 4: Cartilha Água: cada gota conta Fonte: Editora Unifeso (2019).

O grupo formado por exposições, eventos científicos, ciência itinerante, semanas do meio ambiente, feiras/semanas de ciências e tecnologia (41 eventos, representando $13,9 \%$ das atividades) é o responsável pela popularização da ciência, tecnologia e da problemática socioambiental dentro e fora da instituição (figura 5). Dentre as atividades, encontram-se desde eventos locais até eventos na escala nacional, com destaque para a participação na Semana Nacional de Ciência e Tecnologia (SNCT) realizada anualmente na terceira semana do mês de outubro. No presente grupo, encontram-se os eventos com o maior e mais diversificado público, dentre as atividades elaboradas pela Sala Verde Unifeso. 


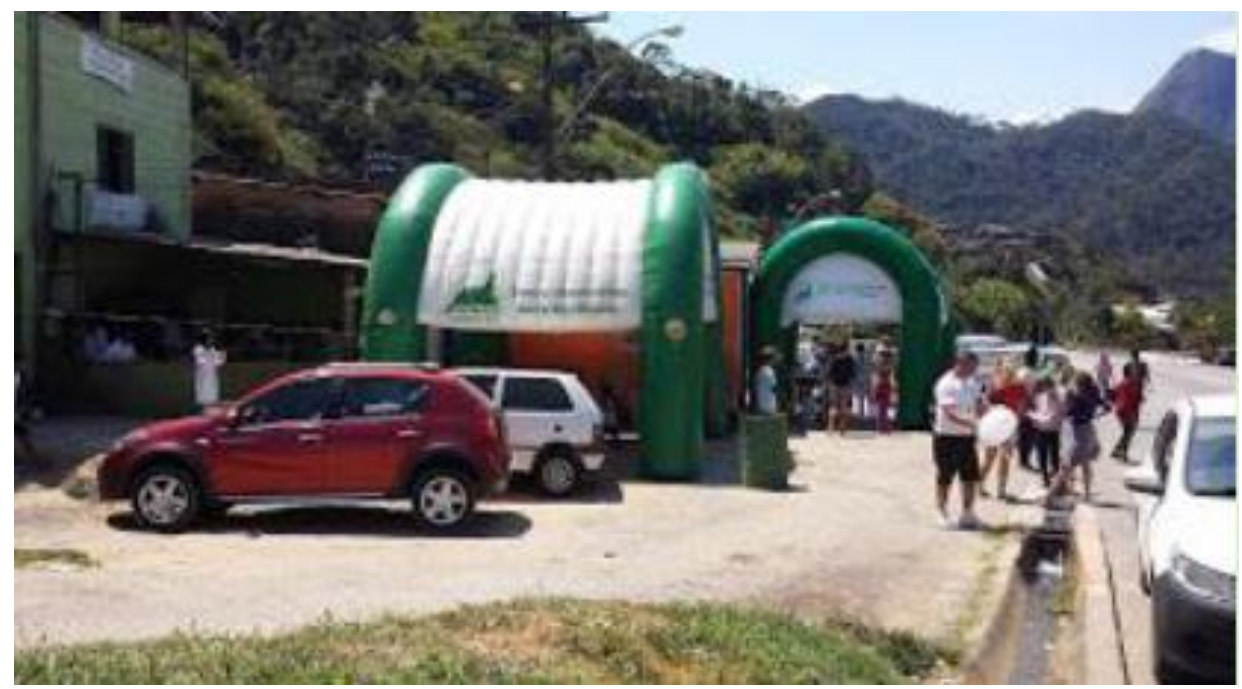

Figura 5: Ciência Itinerante - Ação Social numa comunidade de Teresópolis

Fonte: Unifeso (2017).

Nos seis primeiros anos de existência, a Sala Verde Unifeso foi responsável por divulgar a educação socioambiental, ciência e tecnologia para 7990 pessoas: professores, funcionários e estudantes da instituição, incluindo o Centro Educacional Serra dos Órgãos (CESO), a população local e dos municípios do entorno.

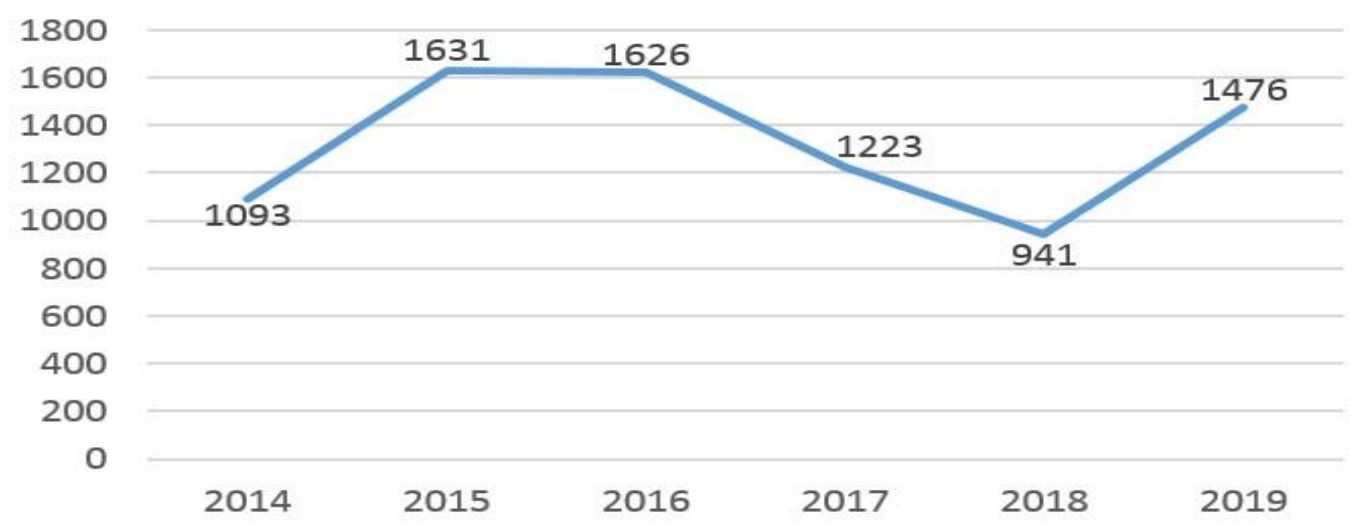

Gráfico 3: Número de participantes nos eventos da Sala Verde Unifeso

Fonte: Elaborado pelos autores (2020).

É importante registrar que algumas atividades não especificaram o público, o que impediu sua contabilização no Gráfico 3. Portanto é correto afirmarmos que o público se encontra subestimado já que foi empregada, nesses casos, a denominação "aberto ao público" no relatório enviado ao MMA. Cabe assinalar que foi encontrada com maior frequência justamente nos eventos com maior quantidade e diversidade de público, como as ações sociais realizadas em praças públicas e os eventos para a popularização da ciência e tecnologia (feiras científicas e o projeto "Ciência Itinerante", do curso de Ciências Biológicas).

Revbea, São Paulo, V. 16, № 4: 191-190, 2021. 


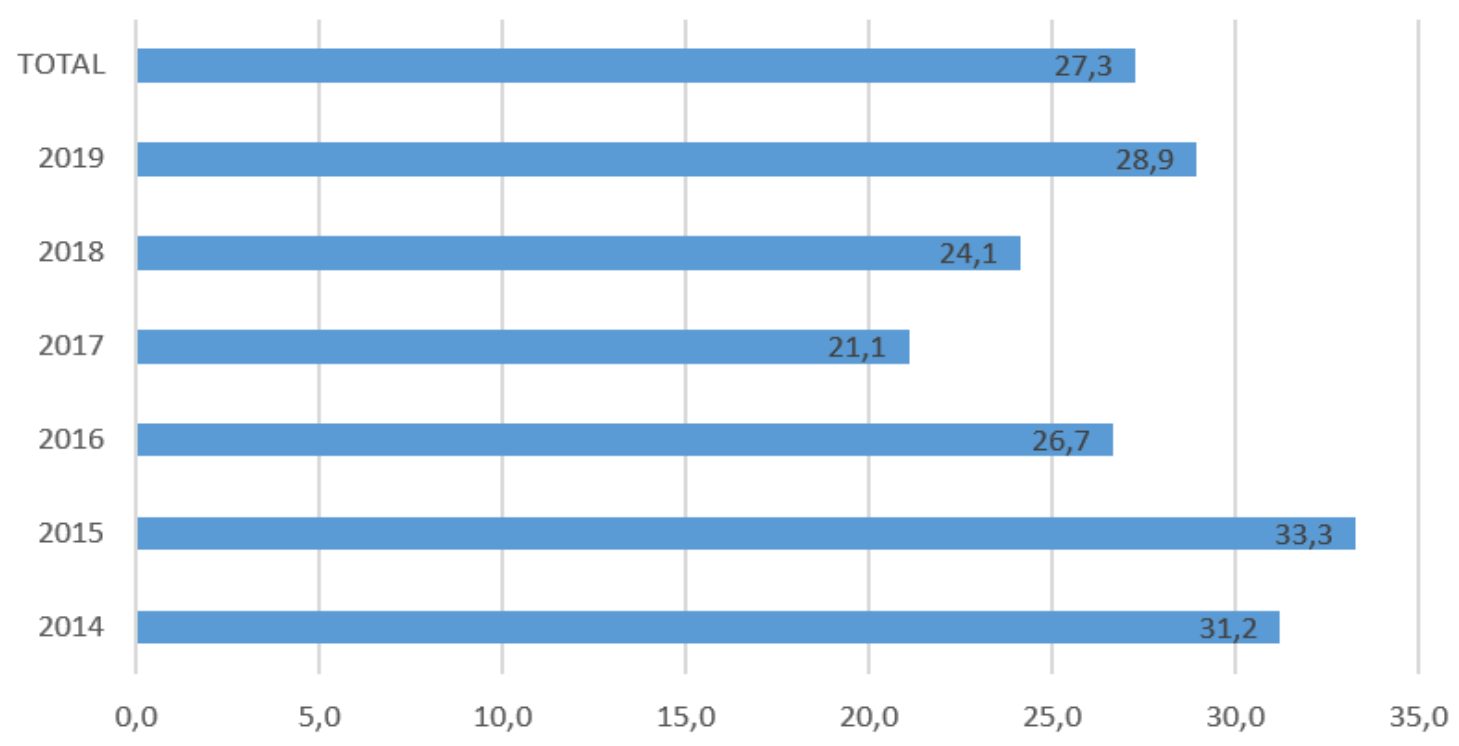

Gráfico 4: Público médio nos eventos da Sala Verde Unifeso

Fonte: Elaborado pelos autores (2020).

Ao analisar o público médio das atividades da Sala Verde por ano, é possível notar que, nos dois primeiros anos de existência, os eventos reuniam mais de 30 participantes, reduzindo o público-alvo de determinadas atividades à medida que as ações se diversificavam e tornavam-se mais específicas. Porém a participação em eventos de maior porte e público mais abrangente nos últimos anos contribuiu para o aumento médio do público por evento.

As atividades da Semana do Meio Ambiente, iniciadas em 2014, foram responsáveis pelo maior público nos anos de 2014, 2015 e 2016, e pelo segundo maior público em 2018. Com exceção do primeiro ano, envolveram mais de 100 estudantes. Em 2019, o espaço temático da Sala Verde "Cada gota conta" (figura 6), no IV Congresso Acadêmico-Científico do Unifeso Confeso, foi visitado por 370 pessoas, tornando-se a atividade com o maior público da Sala Verde até o momento.

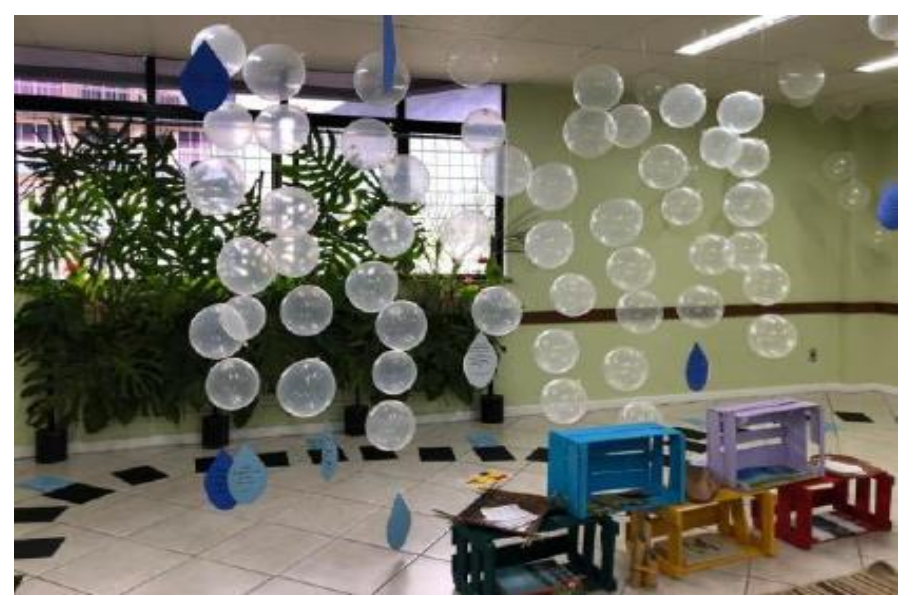

Figura 6: Espaço temático "Cada gota conta" no IV Confeso Fonte: Unifeso (2019). 
Dentre as 293 atividades realizadas, algumas contaram com a participação de convidados internacionais e até de um ex-Ministro do Meio Ambiente. A palestra proferida por Carlos Minc foi a atividade de maior público em 2018, contando com 118 presentes ao evento.

\section{Dificuldades e desafios enfrentados}

Após a descrição das atividades realizadas, o modelo de relatório do MMA indaga as dificuldades e desafios enfrentados no respectivo ano, solicita uma autoavaliação e, para finalizar 0 relatório, sugestões para 0 aprimoramento dos projetos.

No primeiro relatório enviado ao MMA, constatou-se que, apesar da existência oficial de um número significativo de linhas de pesquisa do Unifeso na área ambienta, algumas não apresentavam pesquisas em andamento. Outro ponto importante foi a ausência de projetos financiados com recursos externos, sendo altamente dependentes dos recursos da própria instituição. Dessa forma, um desafio proposto foi o de incentivar o corpo docente da Sala Verde Unifeso a elaborar projetos de pesquisa e extensão na área de atuação da Sala Verde e participar dos editais de agências governamentais e de fomento para a captação de recursos externos. Um outro desafio, ainda não transposto até aquele momento, era ampliar e aprofundar o alcance das ações por meio da articulação interinstitucional (UNIFESO, 2014).

Até o momento, todas as atividades desenvolvidas pela Sala Verde Unifeso foram realizadas com recursos da própria instituição. A ausência de fomentos externos foi um problema registrado em todos os relatórios, sem observar uma perspectiva de melhora (UNIFESO, 2014; UNIFESO, 2015; UNIFESO, 2016; UNIFESO, 2017; UNIFESO, 2018; UNIFESO, 2019).

Assim, para estimular a pesquisa e a extensão em educação socioambiental na instituição, desde 2016, os editais do Unifeso contemplam projetos que dialogam e fortalecem a Sala Verde por meio das bolsas concedidas aos coordenadores e monitores do Plano de Iniciação Científica e Pesquisa (PICPq) e do Programa de Incentivo à Extensão (PIEx).

Outro problema ressaltado nos relatórios entregues é a falta de protagonismo do MMA em promover encontros e diálogo com e entre as Salas Verdes do país. Para suprir tal carência, por iniciativa do UNIFESO, foram firmadas parcerias com importantes instituições atuantes no município, como o Instituto Chico Mendes de Conservação da Biodiversidade (ICMBio) no Parque Nacional da Serra dos Órgãos (PARNASO), em 2016, o Serviço Social do Comércio (SESC) e o Observatório Social do Brasil - Teresópolis, em 2019.

Reiteramos que o ano de 2018 foi o mais crítico no período assinalado, havendo perceptível redução do número de atividades e participantes. Tal redução é creditada aos problemas econômicos e políticos nas esferas municipal e federal, que afetaram direta e indiretamente a instituição (Unifeso, 2018). 


\section{Considerações finais}

Uma preocupação presente desde a concepção da Sala Verde Unifeso foi de não se limitar a ser meramente um espaço físico no qual os materiais informativos enviados pelo MMA, principalmente, são armazenados. Conforme os dados e as informações relatados ao longo do relato de experiência, é possível afirmar que a Sala Verde Unifeso se mostrou extremamente ativa no período assinalado (2014-2019).

A inauguração e consolidação da Sala Verde na instituição foi fundamental para a criação e expansão da Semana do Meio Ambiente, o fortalecimento de linhas de pesquisa referentes à problemática socioambiental, projetos de extensão com funcionários, estudantes e comunidades do município de Teresópolis e o estabelecimento de convênios com ICMBio/PARNASO, SESC e Observatório Social do Brasil - Teresópolis.

Espaços como o da Sala Verde UNIFESO são importantes para a produção de material informativo e didático, a elaboração e execução de projetos de pesquisa, extensão e demais atividades que têm o intuito de expandir a discussão e reflexão sobre a crise socioambiental vigente, em suas múltiplas escalas e inter-relações, e a necessidade da construção de um outro porvir, de futuros desejáveis com justiça social e equilíbrio ambiental, dentro e fora da instituição.

\section{Referências}

BRASIL. Lei $n^{\circ} 9.795$ de 27 de abril de 1999. Dispõe sobre a Educação Ambiental, institui a Política Nacional de Educação Ambiental e da outras providências. Brasília, 1999. Disponível em: <http://www.planalto.gov.br/ccivil 03/leis/19795.htm>. Acesso em: 15 out. 2020.

DIAS, Genebaldo. Educação Ambiental: princípios e práticas.9a ed. São Paulo: Gaia, 2004.

GARCIA, M.; ZANETI, I.; YANOMINE, S.; SILVEIRO, A.; CERQUEIRA, E.; SILVA, M. Duas décadas de PNEA: avanços e retrocessos no Brasil. Revista Brasileira de Educação Ambiental, São Paulo, V. 15, n 5, p. 250-270, 2020. Disponível em: $<$ https://periodicos.unifesp.br/index.php/revbea/article/view/10402/7966> $>$. Acesso em: 15 out. 2020.

GUIMARÃES, M. Educação Ambiental: no consenso um embate? $5^{\underline{a}}$ ed. Campinas: Papirus, 2007.

IBGE.

Teresópolis. Disponível em: <https://cidades.ibge.gov.br/brasil/ri/teresopolis>. Acesso em: 15 out. 2020.

LAYRARGUES, P.:; LIMA, G. As macrotendências político-pedagógicas da Educação Ambiental brasileira. Revista Ambiente \& Sociedade vol. XVII, $n^{\circ} 1$ jan-mar, São Paulo, 2014. Disponível em: 
$<$ https://www.scielo.br/pdf/asoc/v17n1/v17n1a03.pdf>. Acesso em: 01 set. 2020.

LEFF, E. Epistemologia ambiental. 4aㅡ ed. revisada. São Paulo: Cortez, 2007. LOUREIRO, C. Trajetórias e fundamentos da Educação Ambiental. $4^{a}$ ed. São Paulo: Cortez, 2012.

MENDONÇA, F. Geografia socioambiental. Terra Livre. $n^{\circ} 16,1^{\circ}$ semestre. São Paulo, 2001. Disponível em: $<$ https://www.agb.org.br/publicacoes/index.php/terralivre/article/view/352/334>. Acesso em: 01 set. 2020.

REDE BRASILEIRA DE EDUCAÇÃO AMBIENTAL (REBEA). Nota da REBEA aos senhores ministros da Educação e do Meio Ambiente (2019). Disponível em: $<$ https://www.rebea.org.br/images/conteudo/NOTA REBEA FINAL v09-012019.pdf>. Acesso em: 01 set. 2020.

REIGOTA, M. O que é Educação Ambiental? 2a ed. revista e ampliada. São Paulo: Brasiliense, 2009.

PEREIRA, L.A. Sala Verde Unifeso: tecendo a educação socioambiental através de projetos de extensão. Revista Interagir: pensando a extensão. Vol. 1 n. 28. jul. - dez. Rio de Janeiro: UERJ, 2019.

UNIFESO. Projeto Pedagógico Institucional PPI/2016. (2016) Disponível em: $<$ https://www.unifeso.edu.br/instituicao/documentos/ppi2.pdf>. Acesso em: 15 out. 2020.

UNIFESO. Sala Verde. (2020). Disponível em: <https://www.unifeso.edu.br/programas/sala-verde>. Acesso em: 15 out. 2020.

UNIFESO. Relatório anual da Sala Verde Unifeso 2014. Teresópolis: Unifeso, 2014.

UNIFESO. Relatório anual da Sala Verde Unifeso 2015. Teresópolis: Unifeso, 2015.

UNIFESO. Relatório anual da Sala Verde Unifeso 2016. Teresópolis: Unifeso, 2016.

UNIFESO. Relatório anual da Sala Verde Unifeso 2017. Teresópolis: Unifeso, 2017.

UNIFESO. Relatório anual da Sala Verde Unifeso 2018. Teresópolis: Unifeso, 2018.

UNIFESO. Relatório anual da Sala Verde Unifeso 2019. Teresópolis: Unifeso, 2019. 